\title{
ALFONSO DE CARTAGENA Y EL OFICIO DE HISTORIADOR: LAS SEMBLANZAS DE PRÍNCIPES ANTIGUOS Y MODERNOS EN EL DUODENARIUM ${ }^{*}$
}

\author{
Teresa Jiménez Calvente \\ Universidad de Alcalá \\ teresa.jimenez@uah.es
}

\section{Alfonso de Cartagena: un jurista atraído por las letras}

No cabe duda de que la participación de Alfonso de Cartagena en el Concilio de Basilea (1434-1439) fue crucial para la evolución de su pensamiento político y el desarrollo de nuevas aficiones intelectuales. Aunque antes de partir ya poseía fama de erudito y de buen negociador, esta fama se acrecentó a su regreso. Durante las duras sesiones del concilio y en los descansos, trabó amistad con otros importantes prelados y altos funcionarios, muchos de ellos italianos, que le pusieron al tanto de las novedades culturales y literarias bien arraigadas en Italia. Él mismo habla de su buena relación con Ambrogio Traversari, prior de la Camáldula, buen conocedor del griego, a quien solicitó la traducción de la epístola de san Basilio a los jóvenes y de la Funebris oratio de Gregorio Nacianceno; durante el Concilio reanudó su relación con Francesco Pizzolpasso, arzobispo de Milán, quien, a su vez, le facilitó el acceso a Pier Candido Decembrio y Leonardo Bruni, con el que se enzarzó en una agria disputa sobre la traducción latina de la Ética a Nicómaco ${ }^{1}$.

\footnotetext{
${ }^{*}$ Este trabajo se publica en colaboración con el proyecto de investigación Alfonso de Cartagena. Obras Completas FFI 2014-55902-P y FFI 2017-84858-P (MINECO y MICINN, Gobierno de España).

${ }^{1}$ Pizzolpasso fue el primero en leer las críticas del prelado castellano contra la versión de Bruni recogidas en Declamationes; también fue el encargado de remitírselas al canciller florentino, que, por supuesto, dio cumplida respuesta a las objeciones planteadas. Sin embargo, aquella agria polémica se transformó en una buena amistad. Para todo lo relativo a esta disputa, vid. Tomás González Rolán, Antonio Moreno Hernández y Pilar Saquero Suárez-Somonte, Humanismo y Teoría de la traducción en España e Italia en la primera mitad del siglo Xv. Edición y Estudio de la Controversia Alphonsiana (Alfonso de Cartagena vs. L. Bruni y P. Candido Decembrio), Madrid, Ediciones Clásicas, 2000.
} 
Dicha disputa pone ya de manifiesto la fina sensibilidad del flamante obispo de Burgos respecto de materias y disciplinas objeto de revisión y estudio desde las últimas décadas del siglo xIv. Entre esos intereses eruditos, la Filosofía Moral ocupó siempre un lugar relevante, como ya había dejado patente en su primera obra literaria, el Memoriale virtutum, redactada hacia 1425 a raíz de su embajada portuguesa. Aunque sea fruto de la casualidad, esta obra coincide en el tiempo con el Isagogicon moralis disciplinae de Leonardo Bruni, escrita entre diciembre de 1424 y mayo de 1426: en ambas obras se abordan asuntos similares (la definición sencilla de las virtudes) y en ambas se revela el afán de sus autores por pasar de la teoría al ejercicio práctico de la $\operatorname{virtud}^{2}$. Esta preocupación por la moral y la ética y, muy en especial, por las virtudes que debían engalanar a reyes y nobles (al fin y al cabo, los destinatarios naturales de las obras de Cartagena) se conjugaba a las mil maravillas con su interés por otras materias que, por entonces, quedaban adscritas al nuevo canon de los studia humanitatis (la Retórica, la Gramática o la Historia, sin olvidar un cierto interés por la recuperación de los clásicos latinos y griegos) $)^{3}$. A este respecto, es significativo que Cartagena fuese el primero en emplear el término studia humanitatis en España y el encargado de difundirlo entre los destinatarios de sus obras, a los que recordaba la estrecha relación entre esos estudios y el otium provechoso ${ }^{4}$.

\footnotetext{
${ }^{2}$ Es posible leer el Memoriale virtutum en la red gracias a la tesis doctoral de Cristina Martínez Gómez, Estudio, edición crítica y traducción del Memoriale virtutum de Alfonso de Cartagena, Madrid, UCM, 2015 (<http://eprints.ucm.es/40108/1/T37995.pdf $>$ ). Sobre la fecha de composición de la obra, vid. Luis Fernández Gallardo, «Legitimación monárquica y nobiliaria en el Memoriale virtutum de Alonso de Cartagena (c. 1425)», en HID, 28 (2001), pp. 91-128. En cuanto al Isagogicon de Bruni, que hubo de tener una buena acogida en España a juzgar por las dos traducciones al castellano, vid. la tesis doctoral de Montserrat Jiménez San Cristóbal, «El Isagogicon moralis disciplinae de Leonardo Bruni y sus versiones castellanas. Edición y estudio», leída en Madrid, UCM, 2010. De esta misma autora puede verse «La versión castellana del Isagogicon moralis disciplinae de Leonardo Bruni conservada en el incunable 1704 de la Biblioteca Nacional de Madrid», en CFC ELat., 22 (2002), pp. 87-175.

${ }^{3}$ Desde luego, de lo que no cabe duda es que la Poesía, reivindicada con fuerza desde Petrarca en adelante, no formó parte de sus intereses eruditos, centrados en la educación moral de los nobles y prelados llamados a las tareas de gobierno. Sus críticas se hacen expresas en la Epistola al conde de Haro, donde arremete contra la poesía amatoria, bucólica y otras ficciones poéticas («abstinendum erit qui ad inhonestatem videntur allicere, uti sunt amatoria, bucolica aliaque poetarum figmenta»). La edición de esta epístola en Jeremy N. H. Lawrance, Un tratado de Alonso de Cartagena sobre la educación y los estudios literarios, Bellaterra, UAB, 1970.

${ }^{4}$ Vid. Luis Fernández Gallardo, «Los studia humanitatis según Alonso de Cartagena», en Atala$y a, 16$ (2016). [En línea: 13/07/2017]. Enlace: <http://journals.openedition.org/atalaya/1907> [Consulta: 20/03/2018. Aquí, Fernández Gallardo analiza el significado profundo de esos studia humanitatis según los definieron los florentinos Coluccio Salutati o Leonardo Bruni y descubre el valor que otorgó Cartagena a los mismos. Frente a Bruni, que aboga por que los studia humanitatis sean la síntesis perfecta entre las litterae (el dominio de la lengua latina) y la doctrina o «la íntima unión de elocuencia y saber», §5, Cartagena se fija en el carácter subsidiario de la elocuencia, que es útil pero aventaja al conocimiento el conocimiento que pertenece al mundo universitario.
} 
Su interés por la Retórica o elocuencia se inscribe en un marco más amplio, en el que hay que tener en cuenta la situación social de Castilla y del nuevo público lector. Este se sentía atraído por el saber, pero, enzarzado en mil y una disputas, solo podía acceder al mismo si se le dosificaba y presentaba de forma amena. Esto no escapó a la fina inteligencia de Cartagena, que pronto se planteó la relación entre la Retórica (o elocuencia) y el verdadero conocimiento: que los textos estuvieran bien escritos y que se atendiese a la elegancia y buena disposición de los términos eran cualidades que Cartagena apreció en los autores antiguos (no faltan menciones a Cicerón o Séneca) y que no descuidó en sus propias obras. Sin embargo, don Alfonso no se ocupó ni preocupó por la formación del orator (esto era ajeno a sus intereses) y, aunque consideraba la Retórica una disciplina estimable, no por ello dejaba de parecerle accesoria, pues, en su opinión, quedaba por detrás de otros saberes más nobles. Este punto de vista difiere del de los humanistas italianos, que otorgaron a la elocuencia y la Retórica un papel esencial en la formación intelectual de los jóvenes. Para Cartagena, los saberes tradicionales aprendidos en las aulas universitarias seguían siendo prioritarios. La verdadera scientia no tenía nada que ver con la belleza formal de los textos, pues era algo mucho más profundo y de acceso más difícil, una idea recurrente en varias de sus obras y sobre la que vuelve en uno de sus últimos tratados, el Oracional, cap. VII, una suerte de testamento intelectual dirigido a su amigo Fernán Pérez de Guzmán; aquí repasa brevemente sus ideas básicas sobre las virtudes y los saberes en general, de los que habla cuando atiende a las virtudes intelectuales («Intellectu [...], sciencia e sapiencia, que dezimos sabiduría, e arte e prudencia», Oracional, cap. VII), y deja muy claro su parecer sobre la elocuencia, que enjuicia con una clara perspectiva histórica: la elocuencia cultivada en la Antigüedad cambió su curso y razón de ser con la llegada de la nueva fe, con la que el mensaje o res se hizo más importante que el envoltorio 5 .

Su sensibilidad hacia la lengua latina, la Gramática en definitiva, y el uso exacto de los términos se pone igualmente de manifiesto a raíz de su labor como traductor de Cicerón y Séneca. Sin meterse muy de lleno en las

${ }^{5}$ Vid. Alfonso de Cartagena, Oracional de Fernán Pérez de Guzmán. Contemplación sobre el Salmo «Juzgadme Dios». Glosa sobre un prefacio de S. Juan Crisóstomo, Murcia, 1487, de la BNE, I-249(3). Aunque yo cito por esa edición, la obra también puede leerse en la edición de José Luis Villacañas Berlanga, Oracional de Fernán Pérez de Guzmán, en la Biblioteca Saavedra Fajardo (en línea):

$\mathrm{Ca}$ las oraciones desta manera fueron en mucho tenidas en el tiempo pagano que fue llamado gentil. Mas resplandesciente después el sol de la Sancta Fe, tenebresciose algún tanto el resplandor de la lengua. Onde dixo el Apóstol que non predicaua en las persuasibles et dulces palabras de la humana sabiduría, mas en demostración de spíritu et virtud (Cor. 1, 2-4), por que la fe de los oyentes non se fundasse en la sabiduría de los omnes, mas en la virtud de Dios (Oracional, cap. I). 
enfervorecidas discusiones sobre la naturaleza histórica del latín ${ }^{6}$ o la recuperación de la elegancia clásica, sí muestra un cierto interés por el uso de un latín más correcto (incluso llega a plantearse el problema de su ortografía, como se ve en uno de sus comentarios insertos en la Anacephaleosis ${ }^{7}$ ). A resultas de ello, Cartagena se preocupa también por la lengua vernácula y por la posibilidad de transmitir en ella asuntos tan técnicos y especializados como las cuestiones legales o teológicas, algo sobre lo que vuelve también en su Oracional $^{8}$. Ni que decir tiene que el interés de Cartagena por la recuperación y traducción de autores griegos también responde a las nuevas sensibilidades eruditas, que le hacen congratularse por la nueva versión de la República de Platón realizada por Decembrio ${ }^{9}$ o reclamar a su amigo Traversari la traducción de algunos discursos griegos (Duod. II 11, p. 251). En este rápido repaso falta valorar su preocupación por la Historia ${ }^{10}$, disciplina reivindicada con fuerza en los nuevos currículos escolares; de ella me ocuparé de inmediato, aunque adelanto que Cartagena se sintió pronto atraído por esta materia al comprender que podía servirse de ella para reforzar sus tesis políticas y

${ }^{6}$ De todos modos, algo de ello hay en la segunda cuestión del Duodenarium II 10-11, pp. 244-251, donde aborda la antigüedad de las lenguas y su consiguiente prestigio. Al hablar del latín, sigue a san Isidoro y expone su opinión personal de que se trata de una lengua artificial o gramatical que, como el griego del que él había oído hablar a Traversari, solo tiene un registro culto y literario. Para el Duodenarium, vid. Luis Fernández Gallardo y Teresa Jiménez Calvente, El Duodenarium (c. 1442) de Alfonso de Cartagena. Cultura castellana y letras latinas en un proyecto inconcluso, Córdoba, Almuzara, 2015. Todas las referencias a esta obra remiten a nuestra edición.

${ }^{7} \mathrm{Al}$ tratar de la creación de una caligrafía especial por parte de godos, Cartagena habla de su propia época en que los italianos han impuesto una nueva letra inspirada en los antiguos «In Italia tamen a paucis citra temporibus, vetustissimum modum scribendi cum dipthongis qui iam ab usu omnium recesserant, oratores in eloquentiae libris et etiam in epistolis familiaribus seque coeperunt». Tomo la cita de Luis Fernández Gallardo, Alonso de Cartagena (1385-1456). Una biografía política en la Castilla del siglo $X V$, Burgos, Junta de Castilla y León, 2002, p. 308. Esta obra sigue siendo fundamental para cualquier acercamiento a Alfonso de Cartagena y su obra.

${ }^{8}$ Ante la carta de su amigo Fernán Pérez de Guzmán para preguntarle sobre la oración devota y sus frutos, Cartagena, haciendo gala de su modestia, se disculpa por el empleo del castellano y recurre a una eficaz metáfora: si las armas y el caballo son la ciencia y la elocuencia que se expresan en latín, él solo puede servirse del manto y de la espada, que están al alcance de cualquier caballero. Estos dos objetos más humildes corresponden a los saberes que no cuesta mucho adquirir y la lengua vulgar «que llamamos materna sin mixtura de eloquentes palabras» (Oracional, prólogo).

${ }^{9}$ Las cartas intercambiadas entre Cartagena y Decembrio se pueden leer en T. González Rolán, Á. Moreno Hernández y P. Saquero Suárez-Somonte, Humanismo y teoría ..., ob. cit., p. 196.

${ }^{10}$ Para la valoración de la historia por parte de Cartagena resultan fundamentales los trabajos de Luis Fernández Gallardo, «Del uso de la historia o la invención de la Castilla gótica: la Anacephaleosis», en su Alonso de Cartagena (1385-1456)..., ob. cit., pp. 277-319, e «Idea de la historia y proyecto iconográfico en la Anacephaleosis de Alonso de Cartagena», en Anuario de Estudios Medievales, 40:1 (2010), pp. 317 353. Aquí ofrece un pormenorizado análisis de la epístola inicial con que se abre la obra, donde percibe huellas de autores tan reveladores como Cicerón, De oratore II 36, o Terencio. Llega incluso a insinuar que Cartagena pudo haber leído el prólogo de Valla a su historia sobre Fernando de Antequera, donde aparece el tópico horaciano de lo dulce y lo útil. 
aquilatar mejor las enseñanzas morales con las que pretendía moldear a la levantisca nobleza.

Pero, más allá de estos intereses intelectuales, que le permitían llenar con provecho sus escasos momentos de ocio, Alfonso de Cartagena fue siempre y por encima de todo un consumado jurista y, por ende, un erudito fiel al universo escolástico en el que se había educado. Esa formación, adquirida en las aulas de Salamanca, es clave para comprender la labor intelectual y literaria de Cartagena; también a ella se deben sus sonados éxitos en algunas disputas legales en Basilea. Y es que esa fama de buen leguleyo le precedía, como se vio en Aviñón, donde ofreció, de camino hacia Suiza, una lección magistral sobre la Lex Gallus. En la palestra jurídica, Cartagena cimentó sus éxitos en una hábil combinación de los saberes jurídicos con esas otras disciplinas de las que se ha hablado (Retórica, Historia o Filosofía moral ${ }^{11}$, acordes a los nuevos gustos que poco a poco se iban imponiendo). Así, en De praeminentia (1434) defendió la mayor autoridad y prestigio de la monarquía española frente a la inglesa ${ }^{12}$. En las Allegationes super conquesta Canariae (1437), defendió con éxito el derecho de Castilla a conquistar esas islas ${ }^{13}$. En ambas intervenciones, don Alfonso deslumbra por su conocimiento de las leyes y se descubre como un leal y fiel defensor de la monarquía hispánica. Los argumentos legales, que maneja con soltura y precisión, se conjugan en ambos textos con sus apelaciones a la historia de España (que él identifica claramente con Castilla): en el De praeminentia, Cartagena repasa brevemente la historia de las monarquías castellana e inglesa para demostrar la mayor dignidad y honor de Castilla en función de cuatro principios fundamentales: la nobleza de su linaje, su antigüedad, «la alteza de dignidad» y la memoria de los beneficios recibidos ${ }^{14}$. A la hora de hablar de la antigüedad, Cartagena recurre a la

${ }^{11}$ También en el De prebendis, donde Cartagena se ve obligado a abordar el espinoso asunto de las prebendas eclesiásticas en el curso de una disputa conciliar, sorprende el uso que el prelado hace de la Ética a Nicómaco de Aristóteles, que se cuela entre las innumerables citas legales que salpican el texto. En estos momentos, Luis Fernández Gallardo y yo misma preparamos una edición y traducción de este tratado, que esperamos vea la luz en breve.

${ }^{12}$ El título completo de la obra es Propositio super altercatione praeminentiae sedium inter oratores regum Castellae et Angliae in Concilio Basiliensi; sin embargo para abreviar, lo llamaré De praeminentia (Alfonso de Cartagena, Propositio super altercatione praeminentiae sedium inter oratores regum Caste-

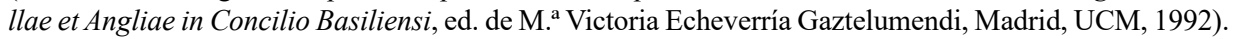
Sobre este texto, vid. también Luis Parra García, «Propositio super altercatione praeminentiae sedium inter oratores regum Castellae et Angliae in Concilio Basilensi o los argumentos de Alfonso de Cartagena por la preeminencia de España», en CFC. ELat, 22 (2002), pp. 463-478.

${ }^{13}$ Vid. Tomás González Rolán, Fremiot Hernández González y Pilar Saquero Suárez-Somonte, Diplomacia y Humanismo en el siglo XV. Allegationes super conquesta Canariae de Alfonso de Cartagena, Madrid, UNED, 1994.

${ }^{14}$ Francisco Castilla Urbano, «Patriotismo y legitimación monárquica en el pensamiento de Alonso de Cartagena: los escritos de Basilea», en Revista Española de Filosofia Medieval, 19 (2012), pp. 139-157, 
historia para concluir que los monarcas castellanos, por derivar directamente del tronco de la monarquía visigoda y estar emparentados con los griegos y romanos, descuellan frente los ingleses. Hay, además, un elemento adicional que otorga ventaja a los castellanos: la continuidad de la corona de Castilla desde los visigodos y, por supuesto, su total independencia con relación a cualquier otro poder, pues nunca se vio sometida ni a los romanos (ya entrevistos por Jiménez de Rada como meros invasores) ni al Emperador. El esfuerzo de documentación histórica realizado entonces no fue baldío, pues Cartagena volvió a utilizar esos datos en el Duodenarium I 2-3, escrito poco después de su estancia en Basilea (1442) para satisfacer la curiosidad de su amigo Fernán Pérez de Guzmán ${ }^{15}$.

El pasado histórico también será un sólido argumento para defender frente a los portugueses el derecho de Castilla a conquistar las islas Canarias. En sus Allegationes, Cartagena recuerda y profundiza en un argumento ya empleado por Alfonso XI en su carta a Clemente VI en 1345: que las Canarias habían pertenecido a sus antepasados, por lo que le asistía el ius regium. Cartagena afina más y, tras consultar las crónicas antiguas y algunos textos legales, concluye que las Canarias formaron parte de la Tingitania, primero en manos de los vándalos $\mathrm{y}$, más tarde, de los visigodos. Aflora aquí el mismo argumento histórico del texto anterior: la conexión directa de los monarcas castellanos con los visigodos al menos hasta don Rodrigo; tras la invasión musulmana, esa línea dinástica siguió viva con don Pelayo, descendiente de la casa real visigoda, y desde él se dilataba hasta Juan II, el rey actual. A partir de aquí, su argumentación se funda en principios jurídicos: para dirimir este asunto eran fundamentales las leyes que regulan las herencias, pues Juan II de Castilla tenía derechos incuestionables sobre esos territorios insulares en virtud de su condición de heredero del reino visigodo.

En ambos casos, don Alfonso muestra una extremada solvencia como jurista, capaz de manejar con soltura los corpus utriusque iuris y, lo que resulta novedoso, de arropar sus argumentos legales con disciplinas ajenas a ese campo. Pero ni en este ni en otros tratados, Cartagena pierde la perspectiva y todo el armazón argumental se subordina a las leyes, por lo que para entender mejor al obispo de Burgos y su acercamiento a las letras hay que tener en cuenta esa formación jurídica que moldeó su pensamiento. Por aquel entonces, la

ofrece un excelente análisis de este texto y de los principios políticos que lo sustentan.

${ }^{15} \mathrm{Al}$ hilo de la primera pregunta, de las cuatro que componen la obra, Cartagena repasa con suma brevedad la historia de las monarquías francesa, inglesa y castellana para apoyar su idea de que el título de rex tiene mayor prestancia y prestigio que el de imperator. Vid. Luis Fernández Gallardo y Teresa Jiménez Calvente, El Duodenarium (c. 1442) de Alfonso de Cartagena ..., ob. cit., pp. 179-181. 
práctica del derecho estaba dominada por lo que más tarde se conocería como mos Italicus, según el cual comentaristas y glosadores, aplicando los métodos discursivos de la escolástica, buscaban la utilización y adaptación de las leyes romanas a casos prácticos reales ${ }^{16}$. Esto presuponía un respeto absoluto por las auctoritates y obligaba a una lectura minuciosa de las leyes: al ser el Derecho Romano verdadera ratio scripta, la labor del jurista consistía en desvelarla. Esta práctica jurídica, plasmada en los comentarios, derivó en una hipertrofia del criterio de autoridad, por lo que desde el siglo XIV se alzaron voces contra este ejercicio de acumulación de citas y autoridades, que a la postre suponía un desprecio por el propio texto legal, enterrado bajo un sinfín de glosas. Dante, Petrarca, Traversari, Filelfo o Valla criticaron estas prácticas y reivindicaron la importancia de la Historia y el latín para poder acometer con mayores garantías la labor jurídica. Al fin y al cabo, había que estudiar el Derecho Romano de acuerdo con su dimensión histórica, como se venía haciendo con otras disciplinas. Cartagena se mueve, por tanto, entre estos dos mundos, el de la tradición medieval, en la que se había formado, y el de los primeros cambios, que no cristalizaron hasta el siglo Xvi con autores como Alciato o Budeo ${ }^{17}$ y la aparición del llamado mos Gallicus o el Humanismo racional.

En su calidad de experto jurista, Cartagena prefiere la lectura literal de los textos, sobre todo cuando la tradición (asentada en la razón y el paso del tiempo) les ha concedido el honor de convertirse en auctoritates y, por eso mismo, en materia no sometida a debate, pues en ellos existe una razón última o una verdad esencial: estos textos se leen con cuidado, se dividen párrafos, se comentan y se interpretan para extraer de ellos las consecuencias lógicas (interpretatio). Interesa descubrir el espíritu de la ley (la ratio legis) y la intención del legislador ocultos tras las palabras. Se trata, por tanto, de utilizar la ratio (razón), clave para entender las leyes escritas y, una vez entendidas, aplicarlas con prudencia a los casos prácticos. En esta búsqueda del espíritu de la ley, que es inmarcesible y remite a una verdad inmutable por ser el Derecho

${ }^{16}$ De hecho, en el Duodenarium II, 7, Cartagena se plantea en qué radica el éxito y perfección del Derecho Romano o ius civile y concluye que este deriva de su perfecta formulación, acorde con la razón:

¿Cuál crees que es la causa de que las leyes de los romanos, que llamamos «derecho civil», sean tenidas en tanta consideración entre nosotros y en algunas naciones que no están bajo el dominio romano a pesar de no tener una autoridad coactiva si no es por el hecho de que sus autores se esforzaron en todo momento en ser fieles a la razón (rationem sequi)?

${ }^{17}$ Vid. Francisco Carpintero, «Mos Italicus, Mos Gallicus y el Humanismo racionalista», en Helmut Coing, ed., Ius commune. Veröffentlichungen des Max-Planck-Instituts für europäische Rechtsgeschichte Frankfurt am Main, VI, Fráncfort, Sonderdruck, 1977, pp. 108-171, ofrece un magnífico resumen sobre los grandes cambios experimentados en la ciencia jurídica desde el siglo xv en adelante. Sobre la enseñanza del Derecho en Salamanca en tiempos de Cartagena, vid. L. Fernández Gallardo, Alonso de Cartagena (1385-1456)..., ob. cit., pp. 60-83. 
un donum Dei, Cartagena desarrolla una especial sensibilidad por el sentido y significado de las palabras. La etimología de los términos se convierte en un buen principio sobre el que apoyar cualquier explicación; luego vendrá el uso de la dialéctica o lógica, que presupone una manera «científica» de presentar las argumentaciones y conclusiones; a partir de aquí, también tendrán cabida esas otras disciplinas, como la historia, la literatura o incluso la propia experiencia vital, que en ocasiones se cuelan en sus tratados más técnicos.

Ese gusto por la literalidad, por el respeto al texto escrito (sobre todo, si este está en latín, griego o en hebreo), tiene también mucho que ver con su interés por las Letras Sagradas, donde es posible adivinar el influjo de su padre, Pablo de Santamaría ${ }^{18}$. El rabino de Burgos estaba acostumbrado a explicar la Biblia a partir de la lectura literal de los textos (poco tenían que ver con el mundo judío las lecturas alegóricas, tan comunes en los comentaristas medievales). Tras su conversión y sus estudios de Teología, tuvo acceso a otras maneras de leer el Antiguo Testamento, pero en una emotiva carta a su hijo Alfonso, que sirve de prólogo a sus Additiones ad Postillas Nicolai de Lyra, le recuerda aquello de que «literalem sensum qui inter ceteros precipuus est» ${ }^{19}$. El comienzo de esta misma carta no puede ser más significativo, pues don Pablo afirma que con esta obra pretende legar a su hijo, como su bien más preciado, sus conocimientos sobre las Sagradas Escrituras para reforzar sus avances «in catholice veritatis solidissimo fervore».

\section{El Duodenarium: el proceso de gestación de la obra}

Pertrechado con estos saberes y bien entrenado en las batallas jurídicas y escolásticas basilienses, Cartagena regresó a España convencido de la importancia de sus conocimientos y consciente de sus responsabilidades civiles y eclesiásticas. Es posible que la distancia le hubiera hecho reparar en los problemas de Castilla, que él compara en alguna ocasión con el agitado Mar Cantábrico $^{20}$. Las guerras intestinas devastaban el reino y, mientras tanto,

${ }^{18}$ Sobre este particular, vid. Teresa Jiménez Calvente, «La mujer virtuosa a ojos de Alfonso de Cartagena: la lectura exegética de Proverbios 31, 10-31 en la cuarta cuestión del Duodenarium», en Tradición y Pervivencia del Mundo Clásico. Homenaje al prof. Eustaquio Sánchez Salor, Alcañiz, Ayuntamiento de Alcañiz-Instituto de Estudios Turolenses, 2018, 21 pp. [en prensa].

${ }^{19}$ Vid. Pablo de Santamaría, Prologus ad Additiones ad Postillas Nicolai de Lyra en Nicolaus de Lyra, Postilla litteralis in vetus et novum testamentum. Expositiones prologorum von Guilelmus Brito; Additiones ad Postillas Nicolai de Lyra von Paulus Burgensis; Replicae contra Burgensem von Matthias Doering, (Genesis, Psalmi, Proverbia, Apocalypsis), Núremberg, Anton Koberger, c. 1481. Cito por el ejemplar de la Bayerische Staatsbibliothek, 2 Inc. c.a. 1079-1.

${ }^{20}$ Cartagena se sirve de esta metáfora en el segundo prólogo de su Duodenarium Prol. 2, p. 269, donde, rememorando tal vez a san Agustín y de una forma muy parecida a como hiciera Petrarca en su 
el enemigo común vivía en paz. Las críticas y los comentarios desdeñosos, como los manifestados por Bruni sobre la imposibilidad de que en España arraigasen los estudios literarios, también hubieron de hacer mella en el espíritu del prelado. Por ello, ya en casa, reforzó su compromiso con la defensa del rey y de la monarquía; tomó conciencia de la importancia de su labor como maestro de los hombres de Iglesia y de la nobleza, a la que había que reconducir hacia la obediencia al rey, y afianzó su patriotismo con una defensa muy activa de Castilla y su misión providencial dentro y fuera de la Península. Si todos se unían en torno a un proyecto común y trascendente, era posible que las aguas se calmasen. Ese proyecto era la reanudación de las guerras contra los musulmanes, con las que se ensanchaba no solo Castilla sino toda la Cristiandad.

En su opinión, el éxito de la empresa no solo dependía de la fuerza militar, pues esta poco podía hacer si no iba acompañada de una renovación moral de los implicados en el proyecto. Aquí entran de nuevo en liza sus disquisiciones sobre las virtudes morales (no vienen al caso ni las teologales ni las intelectuales) y la Historia, que una vez más le da la clave, pues en las crónicas había aprendido que el poderío de Castilla, que alcanzó su momento cumbre con los visigodos, se perdió cuando los pecados arraigaron en la sociedad. El caso de don Rodrigo y sus súbditos era el más claro. Al hilo de estas consideraciones, Cartagena adquiere conciencia de que es preciso modificar las líneas políticas y acometer una profunda renovación moral de la nobleza. ¿Y cómo influir en la moral de los nobles? La respuesta parecía sencilla: con su magisterio de viva voz y por escrito a través de cartas y tratados, compuestos en latín y en romance, en un estilo sencillo para comunicar mejor sus ideas.

En este contexto y al poco de regresar, Cartagena compuso el Duodenarium (c. 1442) para dar respuesta a doce preguntas que le había remitido por escrito su amigo Fernán Pérez de Guzmán. El obispo de Burgos tenía la intención de que las respuestas a esas doce questiones (de ahí el título) conformaran una obra unitaria, una extensa epístola-tratado, según se desprende del extenso prólogo inicial. Esta estructura le había sido sugerida por el De diversis quaestionibus octoginta tribus liber unus de san Agustín, quien había respondido a 83 preguntas en un único libro (Duod. Prol. I 4, p. 178). Pero más allá de este texto concreto, una anécdota incluida en el primer prólogo de la obra apunta hacia san Isidoro como un referente esencial para Cartagena, que ve en el erudito hispalense un modelo intelectual y vital (Duod. Prol. I 1, p.

subida al Mont Ventoux, convierte la contemplación del paisaje en un motivo para la introspección (un comentario del pasaje en Luis Fernández Gallardo y Teresa Jiménez Calvente, El Duodenarium (c. 1442) de Alfonso de Cartagena..., ob. cit., pp. 62-65). 
$164)^{21}$. San Isidoro, al que Cartagena llama Yspaniae iubar, no solo es importante por ser el autor de las Etymologiae, a las que recurre de continuo como una auctoritas básica, pues en el origen de los términos, en los étimos, radica una verdad esencial que permite comprender los conceptos, fundamento indiscutible para la verdadera scientia o conocimiento; de más importante calado son las referencias de Cartagena a unos principios políticos que hacen pensar en el llamado «neogoticismo» de inspiración isidoriana, presente también en Jiménez de Rada, fuente básica para el conocimiento de la historia en Cartagena, y en otras crónicas medievales desde el siglo $\mathrm{XII}^{22}$. La concepción de una unidad territorial y espiritual hispánica gracias a unos monarcas moralmente intachables recuerda mucho el ideario formulado por san Isidoro en sus crónicas y en sus intervenciones en el IV concilio de Toledo.

Cartagena entrevió entonces que ese era el modelo que había que adoptar, pues la historia se mostraba en esto clara y contundente. Al examinar el pasado, la monarquía visigoda, por ser los reyes godos y los actuales de la misma estirpe y por existir una continuidad monárquica ininterrumpida, se presentaba como el modelo indiscutible. Había que distinguir, eso sí, dos periodos diferentes: el de los primeros monarcas, antes de la invasión musulmana (y que coincide, en parte, con lo relatado por san Isidoro en sus crónicas), y otro más reciente, en el que el rey más representativo era Fernando III el Santo, quien unió para siempre los reinos de León y Castilla sentando las bases de una sólida recuperación territorial y moral, la de Castilla núcleo esencial, según su opinión, de España. En este sentido, no es casualidad que Fernando III se erija en modelo de rey ideal en las dos últimas respuestas de la obra (en la tercera respuesta se ofrece una semblanza biográfica del monarca, que es considerado un rey excelente; en la cuarta respuesta, Fernando III es uno de los personajes de la serie de diálogos ficticios allí incluidos) ${ }^{23}$.

\footnotetext{
${ }^{21}$ Cartagena se refiere a una anécdota que aparece narrada en la correspondencia entre san Isidoro y Braulio (Braulio, ep. IV, en Epistolae, PL, LXXX, 651).

${ }^{22}$ Sobre el neogoticismo a lo largo de la Edad Media, vid. Gaël Le Morvan, «La Chronica naiarensis: d'un néo-gothisme astur-léonais à un néo-gothisme castillan», en e-Spania, 7 (juin 2009). [En línea: 18/12/2013]. Enlace: <http://journals.openedition.org/e-spania/18028\#tocto2n4> [Consulta: 4/04/2018). Del mismo autor, Le mythe néo-wisigothique dans la culture historique de l'Espagne médiévale (XII ${ }^{e}-X I I I^{e}$ siècles, París, Univ. de la Sorbona, 2013 (tesis doctoral accesible en < http://www.theses.fr/2013PA040142/ document $>$ ). Resultan también muy útiles las páginas que dedica a este tema Guillermo Alvar Nuño en su tesis doctoral, Estudio, edición crítica y traducción de la Compendiosa historia Hispanica de Rodrigo Sánchez de Arévalo, Madrid, UCM, 2017 (<http://eprints.ucm.es/45373/1/T39361.pdf>).

${ }^{23}$ En esta cuarta respuesta, Cartagena imaginó un diálogo entre Fernando y su madre Berenguela. Sobre esta cuarta pregunta y la respuesta, vid. Teresa Jiménez Calvente, «Alfonso de Cartagena y la cuarta cuestión del Duodenario: hacia un ensayo del género del diálogo», en El Humanismo hispánico en el escritorio y en el mundo. ed. de Ana Vian, número especial de e-Humanista, 29 (2015), pp. 133-151.
} 
Pero el obispo de Burgos advirtió pronto que el planteamiento de la obra era demasiado ambicioso, y no solo porque, desde el principio, lo había diseñado para lograr una difusión mucho más amplia que la sugerida por el molde epistolar impuesto por Pérez de Guzmán. El problema radicaba en que, dada la extensión que estaban tomando las dos primeras questiones, el proyecto difícilmente podría llegar a término. De hecho, la respuesta a las dos primeras preguntas había crecido tanto que pronto se rebasaron los límites de la epístola para adquirir el aspecto de un auténtico tratado. Las dos primeras preguntas formuladas por Pérez de Guzmán tocan de lleno dos temas de absoluta actualidad, alguno muy próximo a los asuntos debatidos por Cartagena en Basilea: 1) si el título de emperador y de rey son idénticos (un tema con una importante carga política, pues ya en el discurso De praeminentia se había dejado claro que los reyes de Castilla nunca se habían sometido al Imperio, lo que les otorgaba una mayor dignidad frente a otras monarquías); y 2) ¿cuál era la lengua primigenia y, por tanto, de mayor prestigio? Para responder a esta segunda cuestión, Cartagena apela a Aristóteles y su concepción del lenguaje expuesta en la Política; a san Agustín y su tratado sobre la mentira; a san Gregorio y sus Moralia y, por supuesto, a la Biblia, en concreto al pasaje de la Torre de Babel, del que extrae importantes conclusiones prácticas sobre el origen de la dispersión lingüística y sobre la relación de las lenguas con la comunidad política (las disensiones nacen de la falta de entendimiento [Duod. II 5-6 y 8, pp. 222-227; pp. 236-239]), y con la justicia (Duod. II 7, pp. 232-236).

Concluida esta primera parte, que él mismo llama Primum Binarium, Cartagena escribió un sucinto «ultílogo» para cerrar el tratado hasta encontrar el tiempo necesario para contestar a las preguntas restantes. Sin embargo, Pérez de Guzmán no quedó satisfecho y reclamó con insistencia y no poca vehemencia las demás respuestas. Así, don Alfonso, aunque estaba muy ocupado, tuvo que volver a la tarea para responder a otras dos preguntas: 3) ¿cuál de los reyes del pasado fue el mejor en virtud y bondad?, y 4) ¿quién es mejor, un hombre excelente o una mujer excelente? Este Secundum Binarium también se encabeza con un prólogo y se concluye con un «ultílogo» que Cartagena ideó como el cierre total del Duodenarium, pues, tras responder a esta cuarta pregunta, decidió abandonar el proyecto. Es más, incluso trató de convencer a su amigo de que esas cuatro respuestas de apariencia miscelánea formaban una obra unitaria con una estructura bien pensada y coherente; así, le descubre la existencia de una disposición quiasmática de las respuestas, en la que la primera pregunta sobre la relación entre los títulos de emperador y rey se corresponde con la tercera y la segunda, con la cuarta y última: 
Aquí tal vez observes, y con razón, que una cuestión se ajusta a la otra, porque en la primera me mandaste discutir sobre la relación, dentro de su género, entre los príncipes supremos a los que llamamos emperadores y reyes. [...] En la segunda, discutiste sobre las lenguas de los pueblos, de cuya diversidad surgió entre esos mismos pueblos una diferenciación completa. Ahora la tercera responde a la primera, para que puedas sopesar la virtud excelente de los príncipes, no entre las dignidades de los reyes, sino entre personas e individuos, y contemples con dulce mirada a algunos de los más excelentes y poderosos. [...] La cuarta parece corresponderse con la segunda, de modo que, como la segunda ha versado sobre la división del género humano, en la cuarta se discute sobre la virtud de los individuos, la de los hombres y la de las mujeres. (Duod. Vtil. II, p. 485-7.)

\section{Las virtudes de los príncipes excelentes en la tercera cuestión del Duo- denarium: la Historia y la educación moral de los nobles}

Cuando Pérez de Guzmán remite su tercera pregunta al obispo de Burgos sobre cuál de los reyes del pasado fue el más virtuoso, Cartagena asegura que va a responder en función de dos premisas: 1) no incluir a ningún príncipe vivo ni «cercano a nuestro tiempo» ${ }^{24}$; y 2 ) elaborar su respuesta a partir de lo que cuentan los libros de historia (Duod. III 1, p. 275). Aquí reside la clave de esta tercera questio, en la que el obispo de Burgos se aventura en el género de la historiografía o, cabría mejor decir, en el oficio de historiador por primera vez en su carrera. Para ello, entre los distintos subgéneros historiográficos, Cartagena escoge la semblanza biográfica, como también haría su corresponsal en sus Generaciones y semblanzas, con lo que, una vez más, ambos se apuntaron a una moda que había calado entre los eruditos italianos al abrigo de las nuevas lecturas de Suetonio, Plutarco y del siempre presente san Jerónimo ${ }^{25}$, pero sin olvidar los modelos patrios más cercanos, como las

\footnotetext{
${ }^{24}$ Es curioso que, en esto, Cartagena coincida con su amigo Pérez de Guzmán, quien en el prólogo de sus Generaciones y semblanzas establece tres premisas básicas que ha de cumplir cualquier historiador; entre ellas, que el historiador sea objetivo y conozca los hechos de primera mano, y «que la estoria non sea publicada biviendo el rey o príncipe en cuyo tiempo e señoría se hordena, por quel estoriador sea libre para escrivir la verdad sin temor» (cito por la edición de Robert Brian Tate, Londres, Támesis, 1965). A este respecto, vid. Teresa Jiménez Calvente, «Teoría historiográfica a comienzos del siglo XvI», en Imágenes históricas de Felipe II, coord. de Alfredo Alvar, Alcalá de Henares, Centro de Estudios Cervantinos, 2000, pp. 197-215.

${ }^{25}$ Sobre el renacer de las biografías seu vitae, vid. Eric Cochrane, Historians and Historiography in the Italian Renaissance, Chicago, Univ. de Chicago, 1981, pp. 393-422, donde recuerda la coexistencia de las biografías escritas bajo el influjo de los modelos clásicos con otras que siguieron fieles a los modelos bien asentados en la tradición medieval, como hagiografías y crónicas.
} 
semblanzas que se incluyen en el De rebus Hispaniae de Jiménez de Rada, que Cartagena utiliza y resume cuando lo considera necesario.

En esta tercera respuesta del Duodenarium, los datos históricos ya no son un argumento más en una disputa jurídica. Aquí, el obispo de Burgos va más allá y, cual cronista, ofrece a su corresponsal un ramillete de vidas ejemplares al lado de otras no tan modélicas; incluso, a pesar de su promesa inicial de basarse solo en lo que encuentra escrito y dejar de lado a los príncipes más recientes, se atreve a pergeñar, a modo de conclusión, los sucintos retratos de dos soberanos a los que había conocido personalmente: Enrique III el Doliente y Fernando de Antequera o Fernando I de Aragón, modelos ambos de monarcas excelentes. Estas dos semblanzas, añadidas a última hora, nos permiten comprobar la destreza de Cartagena como biógrafo, o más bien cabría decir rhetor, pues, apoyado exclusivamente en sus recuerdos y vivencias, compone dos auténticos panegíricos. De igual modo, ambas vidas servirán para reforzar el mensaje político que recorre, a la postre, toda la respuesta.

Ante la novedad de reto y antes de meterse en faena, Cartagena se siente en la obligación de esbozar, siquiera de manera sucinta, su opinión sobre el valor de las crónicas y los cronistas, una manera de hacerse eco de un debate en pleno auge sobre el que volvió en el prólogo a su Anacephaleosis $^{26}$. Al fin y al cabo, la tradición tanto clásica como medieval imponían al historiador/ cronista dedicar unas palabras iniciales a la valoración de esta disciplina y su relación con todas las demás ${ }^{27}$. Sus opiniones a este respecto se inscriben en el marco mucho más amplio de su concepción general de los saberes, que queda resumida de manera sencilla en ese testamento póstumo que es el Oracional (cap. VII) y que aquí me servirá de guía. Su visión está en sintonía con la jerarquización de esos saberes propuesta por santo Tomás, quien se hacía eco de las formulaciones previas de Casiodoro, Boecio y, a la postre, del propio Aristóteles ${ }^{28}$. Si los saberes pueden versar sobre lo contingente y lo no-contingente o necesario, la verdadera sabiduría solo se adquiere a partir del estudio de lo no-contingente. Quienes se dedican al estudio de Dios y de las cosas sagradas tienen el mayor reconocimiento, pues Él es principio de

${ }^{26}$ Alfonso de Cartagena, Anacephaleosis, ed. de Roberto Bell, Rerum Hispanicarum Scriptores aliquot, Fráncfort, Wechel, 1579.

${ }^{27}$ Sobre esta tradición bien arraigada entre los cronistas españoles del Medievo, vid. Luis Fernández Gallardo, «De Lucas de Tuy a Alfonso el Sabio: Idea de la Historia y proyecto historiográfico», en Revista de Poética Medieval, 12 (2004), pp. 53-119.

${ }^{28}$ A este respecto, resultan muy interesantes las apreciaciones de Luis Fernández Gallardo, «Idea de la historia y proyecto iconográfico...», art. cit., pp. 323-324. También muy sencilla y clara resulta la exposición de Cartagena sobre esta jerarquía del conocimiento en su Epistola al conde de Haro (vid. Jeremy N. H. Lawrance, Un tratado de Alonso de Cartagena ..., ob. cit.). 
todo y no hay nada superior. Luego vendrán los otros sabios, cuya sciencia consiste «en saber las cosas eternas et nescesarias, que non son contingentes nin declinan a ser o non ser». Este tipo de conocimiento se obtiene «sacando verdaderas conclusiones de los principios primeros por demostración, que es prueua muy cierta, commo faze la Philosophía natural et las sciencias que della dependen». A este segundo grupo pertenecen quienes se entregan al estudio más especulativo, como los que se ocupan de la filosofía natural o la metafísica. En último lugar, están los que poseen saberes más prácticos, que se dirigen no tanto a descubrir la verdad como a la acción (que corresponde al «arte e prudencia» [Oracional, cap. VII]).

De acuerdo con este esquema, ¿dónde se sitúan los cronistas? Para empezar, en su tercera respuesta, Cartagena compara la labor del cronista tradicional con la del juez. ${ }^{29}$. En su opinión, el cronista no es más que un testigo privilegiado de los hechos y su labor debe limitarse a consignarlos por escrito, por lo que resulta muy peligroso dejarse guiar exclusivamente por su parecer desnudo (cronistarum sententiam nudam sequi [Duod. III 2, p. 282]). Por el contrario, al juez le corresponde juzgar esos hechos, y esta es la actitud que aconseja a quien se acerca a las crónicas en busca de ejemplos de reyes buenos y malos:

No de manera distinta debemos silogizar en las crónicas, para aprender también en la serie de las historias qué hicieron los reyes de antaño. En función de aquellas acciones que salieron bien, según las hemos aprendido en las historias, conviene juzgar, con nuestra razón como guía y con las enseñanzas de los sabios, a dichos reyes como buenos o malos y qué grado de bondad o maldad debemos atribuirles (Duod. III 2, pp. 283-285).

Sin embargo, Cartagena aprecia una diferencia entre la labor del cronista de siempre, visto muchas veces como un mero compilador de datos, y la que ahora le ha tocado acometer, ya que su sólida formación académica le capacita para «silogizar» y aplicar criterios racionales al escrutinio de los datos. Una vez entresacados, deberá combinarlos para tejer un relato coherente con fines didácticos y políticos. En este caso, no se trata de escribir una crónica para ensalzar a un soberano particular ni una historia general de España, proyecto que activó al final de su vida con la Anacephaleosis, donde, amparado

${ }^{29}$ Aunque aquí no lo dice, está claro que para Cartagena los jueces pertenecían a una categoría superior, pues se les presuponía un conocimiento de las leyes adquirido en las aulas. De este modo, les correspondería una suerte de scientia por emplear la razón y los principios básicos de la lógica como herramientas para desentrañar el sentido último de las leyes. Este carácter excelso de los jueces se pondera en Duod. III 5-6, pp. 294-302, donde se les considera una suerte de «hijos de los reyes», porque en ellos recae la ejecución de la justicia distributiva, en la que se asienta la paz del reino. 
en su auctoritas y ratio, se atrevió a enjuiciar, en cierto sentido, a los reyes del pasado ${ }^{30}$. Ahora, en pos de un objetivo político y didáctico bien definido, le corresponde espigar, a partir de una grueso catálogo, las vidas de doce monarcas o, si se quiere, príncipes (un número claramente significativo en una obra que se titula Duodenarium). Para justificar esa elección, Cartagena realiza una evaluación previa y general de las virtudes que ha de poseer un príncipe excelente. Una vez seleccionadas las virtudes, se escogen las biografías de algunos principes que, en función de esas virtudes y no otras, pueden ser considerados buenos o malos. A la postre, el programa de Cartagena supone una vuelta de tuerca a lo expresado por Jiménez de Rada, su fuente fundamental para los reyes godos, en el prólogo de su De rebus Hispaniae, cuando señala que la recopilación de las gestas de los príncipes permite averiguar cuáles fueron nefastos y cuáles virtuosos en relación con cuatro virtudes fundamentales (sapientia, strenuitas, largitas et iustitia):

Gesta etiam principum, quorum aliquos ignauia fecit uiles, alios sapiencia, strenuitas, largitas et iusticia futuris seculis comendauit, ut quanta sit diferencia utrorumque exitu comprobetur, et discant posteri bonorum exemplis inniti et a malorum semitis declinare ${ }^{31}$.

Pero Rada como cronista no enjuicia, sino que se limita a consignar los hechos, pues será el lector o el propio devenir histórico el encargado de juzgar a los protagonistas. Cartagena, de entrada, actualiza y modifica levemente esas cuatro virtudes esenciales al hilo de lo leído en santo Tomás y, por supuesto, Aristóteles, Cicerón y Séneca. En su caso, esas virtudes son, por orden de importancia, iustitia, fortitudo, liberalitas et magnificentia, todas ellas de inspiración clásica y que, según sus propias palabras, «cada una de ellas va encaminada al bien de los demás» (Duod. III 4, p. 293). Gracias a esta nueva concepción en la que lo tradicional y lo nuevo se dan la mano, sin perder de vista al destinatario del texto, su amigo Pérez de Guzmán, representante de una nobleza diletante y mundana, Cartagena selecciona los príncipes que han de ser considerados virtuosos o ímprobos. Esta selección es el resultado de un juicio previo en el que el veredicto a favor o contrario se revela en el título que da paso a cada semblanza; tras él, las biografías dan

\footnotetext{
${ }^{30}$ Hago aquí mía la valoración de L. Fernández Gallardo, «Idea de la historia y proyecto iconográfico...», art. cit., p. 326, quien concluye que en la Anacephaleosis «el interés histórico de Alonso de Cartagena es primordialmente político: antes que a una historia nacional aspira a una historia del poder, más bien de la serie quienes lo ejercieron».

${ }^{31}$ Vid. Rodrigo Jiménez de Rada, Historia de Rebus Hispaniae sive Historia Gothica, ed. de Juan Fernández Valverde, Turnhout, Brepols, 1987, p. 6.
} 
cuenta de las mencionadas virtudes siempre en función de los datos extraídos de las crónicas.

Este interés de Cartagena por la Historia y su uso didáctico-moral se expresa también en su Epistola al conde de Haro (Epistula directa ad inclitum et magnificum virum dominum Petrum Fernandi de Velasco, comitem de Haro), escrita hacia 1440, nada más volver de Basilea ${ }^{32}$ y que, una vez más, se dirige a un miembro de la nobleza conocido por su afición a los libros y la lectura. En ella, don Alfonso habla de la apetencia natural del hombre por el estudio, de la que ya habló Aristóteles y que se convirtió en un auténtico communis $\operatorname{locus}^{33}$. A pesar de ello, no todos experimentan idéntica pasión por el saber, por lo que es posible establecer tres tipos de hombres (Ep., pp. 35-6): los que dedican su vida entera al estudio («audiendo, legendo scribendoque»); los que se acercan al estudio de forma esporádica y los que nunca han tenido relación con él. Los primeros son los únicos que pueden aspirar a la verdadera sabiduría; los segundos deben aceptar que hay disciplinas que les están vedadas, como las que pertenecen al ámbito escolástico y teológico, y otras que están a su alcance; de ellas, algunas perjudican la moral (como la poesía amatoria y bucólica) y otras son recomendables, como las crónicas, que poseen una función pedagógica clara: «Cronique quoque militaribus viris perutiles sunt». Además, hay que tener en cuenta que todo lo que se lee debe ir encaminado a dirigir la moral («cum omnia ad dirigendos mores nostros reducenda sint»). De ahí que sean más útiles los escritos que narran cosas verdaderas que los que se demoran en ficciones («ille tamen que vera, non que ficte composita narrant»); por lo tanto, los «milites viri», como su amigo el conde de Haro o el propio Pérez de Guzmán, deberían dedicar su tiempo libre (el famoso otium) a leer textos que los hagan mejores y, entre los libros de los gentiles que les están permitidos, destacan los de materia «sive scientifica», que se ocupan de la definición de las virtudes (cita expresamente a los filósofos Platón y Aristóteles), «sive persuasoria», que gracias a su estilo elocuente incitan al cultivo de esas mismas virtudes (a esta categoría pertenecen Cicerón o Séneca), «sive ystorialia» ${ }^{34}$ :

\footnotetext{
${ }^{32}$ Todas las citas de la epístola parten de la edición de Jeremy N. H. Lawrance, Un tratado ..., ob. cit.

${ }^{33}$ Cartagena se sirvió en varias ocasiones de esta cita aristotélica; así ocurre en el prólogo a su traducción del De senectute de Cicerón; en el prólogo del De providençia de Dios (traducción del tratado de Séneca), en la Epístola al conde de Haro o en su Anacephaleosis. Ángel Escobar Chico analiza el uso que hace Cartagena de la cita aristotélica en «El Aristóteles de Alfonso de Cartagena: hacia una valoración de conjunto», en Atalaya, 16 (2017). [En línea: 13/07/2013]. Enlace: <http://journals.openedition.org/ atalaya/1903> [Consulta: 13/04/2018].

${ }^{34}$ Jeremy Lawrance, Un tratado..., ob. cit., p. 53, n. 60, señala otros lugares en que Cartagena marca las diferencias entre Aristóteles y Cicerón o Séneca, de manera que al primero lo califica de scientificus mientras que a Cicerón solo de eloquens.
} 
Et illis ergo que ad mores regendos docendo vel excitando prodesse possunt, sive scientifica, sive persuasoria sive ystorialia sint, aliqua summere et in aliquibus occupari prout uniuscuisque animus intensius inclinatus militaribus viris congruum iudico (Ep., p. 54).

Cartagena ofrece, así, una nueva visión de la historia, género que comparte una serie de rasgos con los tratados de moral o filosofía práctica, como los de Cicerón o Séneca. Esta proporciona, por un lado, exempla que sirven de modelo de comportamiento; por otro, posee un carácter elocuente o retórico que le permite incitar a la acción. Por tanto, quien desee escribir historia, aunque no sea un sabio stricto sensu, ocupa una posición intermedia entre este y un mero compilador, porque debe manejar la elocuencia y un cierto conocimiento de las virtudes, lo que supone una tímida vindicación de un nuevo tipo de cronista que él pretende encarnar: el erudito que compila los hechos, enjuiciándolos con la razón, en pos de una intención política o didáctica clara ${ }^{35}$. Este, además, debe hacer gala de cierta capacidad retórica para que el relato sea ameno y efectivo ${ }^{36}$. A su vez, quien lee estos textos (siempre preferibles a las novelas de caballerías) encuentra en ellos un medio adecuado para satisfacer sus ansias de conocimiento (algo connatural al espíritu humano). Una vez más, Cartagena resuelve el conflicto con fidelidad a su concepción del saber, pero sin rechazar nada de lo que le brindaban las nuevas disciplinas.

De vuelta a esta tercera respuesta del Duodenarium, Cartagena la divide en dos grandes bloques: 1) en el primero (Duod. III 1-9, pp. 275-311), el obispo de Burgos realiza unas consideraciones generales sobre las virtudes que han de engalanar a cualquier príncipe para que sea considerado un buen

${ }^{35}$ Este deseo de aunar el relato historiográfico y la moral estuvo en la base de un proyecto que nunca llegó a buen puerto: la composición de un auténtico De dictis et factis memorabilibus, como el de Valerio Máximo, centrado en España y la Cristiandad. Fue su discípulo Diego Rodríguez de Almela quien, al final, dio cuerpo a este proyecto con el Valerio de las historias escolásticas e de España, editado en Murcia en 1487. El propio Rodríguez de Almela confiesa en el prólogo de la obra que no hacía sino completar el proyecto de Cartagena, en cuya casa había ingresado cuando tenía 14 años: «En su vida cognoscí ser su deseo que, como Valerio Máximo de los fechos romanos e de otros fizo una copilación en nueve libros.... que así su merced entendía fazer otra copilación de los fechos de la Sacra Scriptura e de los Reyes de España, de que cosa alguna Valerio non fabló, lo qual él fiziera en latín escripto en palabras scientíficas e de grand eloquencia si biviera» (cito por el I/249 [1] de la BNE).

${ }^{36}$ Este valor ejemplarizante de la historia está también detrás de su Anacephaleosis, concebida en primera instancia para mostrar de manera sencilla al rey Juan II, por medio de árboles genealógicos y retratos cargados de simbolismo, una historia de España en la que se alababan las virtudes y se ponían de manifiesto los vicios de sus antecesores. Como indica Luis Fernández Gallardo, «Idea de la historia y proyecto iconográfico...», art. cit., pp. 322-25, don Alfonso expone con mayor profundidad su concepción de la historia en el prólogo de esta obra, donde concluye que el que escribe historia no necesita mucha ciencia, ni una capacidad excesiva, aunque esta ha de ser superior a la media («quod nec ingenii altitudinem poscit, nec etiam capacitatem, licet mediocrem aut paruam transcendit, contemnendum non est»). 
gobernante; 2) en el segundo (Duod. III 10-21, pp. 311-360), ejemplifica esas virtudes a través de las biografías de 6 príncipes virtuosos y, para que sus virtudes resulten más nítidas, se oponen a las de otros 6 príncipes malvados. Para la primera parte, como se ha indicado, Cartagena tiene muy presente la Ética a Nicómaco de Aristóteles ${ }^{37}$, pues, para su selección de las virtudes, solo considera las que pertenecen al ámbito de las virtudes morales (iustitia, fortitudo, liberalitas et magnificentia) ${ }^{38}$; en su opinión, ni las virtudes teologales ni las intelectuales determinan la bondad de un príncipe, aunque tampoco están de más. Nunca hay que perder de vista que, en su opinión, los príncipes están sometidos a una doble consideración: una como hombres que son, y otra como príncipes. Ser un hombre bueno, poseedor de las principales virtudes, no implica ser un buen gobernante. Sin embargo, si un príncipe es tildado de buen gobernante, habrá que suponer que, además, es un hombre bueno. En todo este planteamiento hay una cierta apreciación del devenir histórico, pues considera que, a pesar de que a los gentiles no se les pueden pedir las virtudes teologales, algunos sí pertenecieron a la categoría de buenos príncipes (y, por tanto, de hombres buenos también). De estas cuatro virtudes, que son comunes a todas las razas, pueblos y épocas, las dos primeras son indispensables; las otras dos otorgan brillo y relumbre al principado (Duod. III 3, p. 291).

En su selección de príncipes buenos y malos, Cartagena admite a los gentiles y, tras eliminar a Salomón, Alejandro Magno, Aníbal o Augusto, se queda con los emperadores romanos, cuyas historias son más conocidas por el público. Don Alfonso escoge una terna de emperadores romanos excelentes que se contraponen a otros tres emperadores malvados. A continuación, repite este esquema con los príncipes españoles. Esto le resulta más difícil, pues siempre habrá quien se sienta dolido o esté en desacuerdo con la selección. En este segundo grupo, no obstante, establece una distinción entre los príncipes más antiguos (aquellos que reinaron cuando la monarquía abarcaba un territorio más extenso, tenían una «manera de hacer política» diferente e

${ }^{37}$ Sobre el aristotelismo en la España del Cuatrocientos, vid. Carlos Heusch, «El renacimiento del aristotelismo dentro del humanismo español», en Atalaya, 7 (1996), pp. 11-40. También Ángel Escobar Chico, «Sobre la fortuna de Aristóteles en España», en Revista Española de Filosofia Medieval, 1 (1994), pp. 141-148, y la tesis doctoral de María Díez Yáñez, El noble virtuoso: la recepción de la Ética aristotélica en la Castilla tardomedieval y renacentista, Madrid, Universidad Complutense, 2015 ( $<\mathrm{http}: / /$ eprints.ucm.es/33240/>).

${ }^{38}$ Estas virtudes también habían recibido un tratamiento muy pormenorizado en el Memoriale virtutum (c. 1425), dirigido al príncipe don Duarte, y concebido como una suerte de resumen de las charlas que ambos habían mantenido sobre ese tema durante la embajada portuguesa de Cartagena. Sobre esta obra, vid. Luis Fernández Gallardo, «Legitimación monárquica...», art. cit., y la tesis doctoral de Cristina Martín Gómez, Estudio, edición crítica y traducción ..., op. cit. 
incluso sus nombres eran distintos [《ipsorum eciam nominum dissimilitudo»] [Duod. III 18, p. 342]) y los más recientes. Y para que el espíritu jocoso que preside la epístola no desaparezca, propone a su amigo escoger príncipes que se llamen Alfonso o Fernando. Al final, la lista completa es la siguiente: Tito, Trajano y Teodosio se contraponen a Domiciano, Nerón y Juliano el Apóstata. Entre los españoles, Recaredo se contrapone a Witiza, Alfonso el Católico a Mauregato y Fernando III ${ }^{39}$ a Alfonso el Monje ${ }^{40}$.

\section{Las semblanzas de Enrique III de Castilla y Fernando de Antequera}

Una vez concluido este «duodenario» de príncipes, don Alfonso rompe su promesa, como ya se señaló, y decide ofrecer a su corresponsal las semblanzas de dos príncipes a los que había conocido personalmente ${ }^{41}$; con ello, añade a la respuesta siete capítulos más (Duod. III 22-28). Aunque esta forma de proceder supone una ruptura del plan inicial, don Alfonso se resiste a desbaratar las simetrías que tanto le gustan y otorga a estos capítulos finales la categoría de epílogo o recapitulación. Con suma maestría, se replantean temas ya tratados a lo largo de toda la respuesta, que adquieren mayor cercanía y presencia por estar referidos a dos reyes casi contemporáneos. Por ello, no ha de extrañar que Cartagena vuelva a incidir sobre el valor de la Historia y el oficio del cronista en unas palabras iniciales que recuerdan lo dicho por Jiménez de Rada y su consideración de la Historia como un tipo de escritura encaminada a preservar hechos y hazañas que la posteridad deberá imitar o rechazar $^{42}$. Al hilo de esta consideración, Cartagena da un paso más y lanza una advertencia dirigida a cualquier príncipe de cualquier lugar: todo lo que los príncipes hacen queda en la memoria de la posteridad, por lo que siempre deberán comportarse con la mente puesta en que todos los miran y enjuician (una sucinta referencia al organicismo político tan presente en la tratadística

\footnotetext{
${ }^{39}$ Junto con las dos semblanzas añadidas posteriormente, la vida de Fernando III es una de la más personales y trabajadas, como señalé en L. Fernández Gallardo y T. Jiménez Calvente, El Duodenarium (c. 1442)..., op. cit., pp. 117-119.

${ }^{40}$ Para las características de estas semblanzas y algunas precisiones sobre sus fuentes, vid. L. Fernández Gallardo y T. Jiménez Calvente, El Duodenarium (c. 1442)..., ob. cit., pp. 81-86 y 110-120.

${ }^{41}$ Don Pablo de Santamaría, en la carta a su hijo Alfonso que da inicio a sus Additiones ad Postillas Nicolai de Lyra, rememora su familiaridad con el rey Enrique («cum tamen in domo gloriose memorie iustissimi regis Enrici quam eius illustris plante inclyti regis nostri Sigismundi officio suscepto satis familiariter sum versatus»). El propio Cartagena recuerda también en Duod. III 25, p. 368 sus visitas de niño al palacio de los dos jóvenes príncipes, cuyas virtudes lo admiraban ya entonces.

${ }^{42}$ Así, Cartagena asegura: «nec enim cronice nobis traduntur ut antiquorum gesta solum sciamus, set ut scientes deuitemus turpia et sequamur honesta» (Duod. III 22, p. 360).
} 
del siglo $\mathrm{Xv}^{43}$ ). Es más, el tiempo siempre proporciona libertad para juzgar los hechos sin la presión del temor o la adulación: «Ciertamente la posteridad hablará de nosotros con libertad, al igual que nosotros hablamos libremente de los que nos han precedido» (Duod. III 22, p. 361).

Tras esas consideraciones iniciales y a fin de respetar los esquemas previos, Cartagena esboza dos sucintas semblanzas de estos dos príncipes recientes (Duod. III 23-24); luego, a fuerza de completar y ampliar los datos (Duod. III 25-27), las convierte en elogios que poseen una intención didáctica clara: los monarcas, siempre sometidos al escrutinio general, deben ser ejemplos vivos en todas sus acciones ante sus súbditos, los presentes y los futuros, algo que siempre cumplieron, según su opinión, Enrique III y Fernando I de Aragón. Estos fueron unos príncipes tan magníficos y están tan próximos en el tiempo que permiten abrigar buenas esperanzas sobre el futuro de España y la monarquía. De ese modo, como broche absoluto para su tercera respuesta (Duod. III 28), Cartagena lanza un mensaje positivo, pues frente a lo que ocurrió en épocas pretéritas, en el presente no hay príncipes nefastos que oponer a los dos homenajeados:

Así que alégrese esta edad moderna, que con frecuencia reniega de su época, de que en esta parcela de tiempo ha habido algunos hombres de bien y de que, sin embargo, no se encuentra ningún príncipe ímprobo de maldad reseñable (Duod. III 28, p. 383).

Don Alfonso, convertido en cronista ocasional, no necesita recurrir a las fuentes escritas para componer estas dos semblanzas: las opiniones favorables en boca de todos ${ }^{44}$ y sus propios recuerdos son suficientes. Lejos de la parquedad de las vitae anteriores, en las que el prelado se limitaba a recoger los datos sin añadir apenas comentarios, ahora cambia el registro y eleva su tono. Incluso, de cuando en cuando, don Alfonso lanza el guante a Pérez de Guzmán, a quien interpela y hace partícipe de sus razonamientos

\footnotetext{
${ }^{43}$ Un buen resumen de este pensamiento político durante el siglo xv puede leerse en Guido Cappelli, «Conceptos transversales: república y monarquía en el Humanismo político», en Res publica, 21 (2009), pp. 51-69 e Id. , «Exemplar mundi: el príncipe renacentista como 'ejemplo del mundo'», en Despalabro: Ensayos de humanidades, 5 (2011), pp. 129-137.

${ }^{44}$ Es curioso comprobar que este consensus general sobre las virtudes morales de Enrique III se mantiene en la Compendiosa historia de Rodrigo Sánchez de Arévalo, discípulo de Cartagena y autor de una de las primeras crónicas generales de España en ver la luz de forma impresa (Roma, 1470). En esta obra, que debe muchísimo a la Anacephaleosis de su maestro, nada más comenzar el cap. XXIII de la cuarta parte dedicado a Enrique III se señala que, en su caso, no va a centrarse «tanto en el desarrollo de su reinado como en su forma de vivir, y no tanto en cuánto tiempo reinó, sino más bien en con cuánta piedad, rectitud y justicia vivió» (la obra puede consultarse en la edición de G. Alvar Nuño, Estudio, edición crítica..., ob. cit., p. 818).
} 
(«Considera quipe quanta fide et deuotione sanus polleret» [Duod. III 23, p. 364]; «conspice nunc quales hii duo fratres et an inter optimos principes sint ponendi» [Duod. III 25, p. 366]; «tu et multi ex viventibus [...] testari possent» [Duod. III 25, p. 368], etc.), un procedimiento que ya había empleado en su vida de Fernando III. Basta comparar esta semblanza de Enrique III con la que años después incluyó en su Anacephaleosis, cap. XCI, para apreciar las diferencias de tono y contenido: si en esta vita los datos se comentan, ponderan y ensalzan, años después se ofrecen de manera aséptica, aunque en las indicaciones para el retrato pictórico se insiste en que Enrique fue un rey justo y caracterizado por la gravedad de sus costumbres («ensem habens in manu propter grauitatem morum et iustitiae zelum quem habuit»).

En todo momento, Cartagena se escuda en ese sentir general positivo y está seguro de que todos, y su interlocutor el primero, estarán dispuestos a corroborar sus afirmaciones: Enrique gobernó con justicia a pesar de su corta edad y su mala salud; poseyó, además, fortaleza de su ánimo y ardor guerrero, que le llevaron a planear la reanudación de la guerra contra los musulmanes, un proyecto truncado por su prematura muerte, que lo sorprendió en Toledo la mañana de Navidad. Esta sucinta exposición encierra todos los ingredientes en los que basar el elogio: Enrique se presenta como un auténtico puer senex, defensor de la justicia y pacificador de un reino siempre levantisco. Incluso los pormenores de su óbito brindan de él la imagen de un príncipe muy religioso y piadoso, pues, al alba, solicitó a los presbíteros el oficio Puer natus est nobis y, mientras lo escuchaba, expiró ${ }^{45}$.

Tras esta breve presentación, viene el elogio de Fernando con un tono semejante, aunque lo primero que se destaca es su lealtad hacia Enrique durante los años de regencia. Así, Fernando se presenta como un mero continuador de los proyectos bélicos de su hermano hasta su llegada al trono de Aragón. Una vez nombrado rey, supo ganarse a la nobleza aplicando la máxima virgiliana de perdonar a los obedientes y contener a los rebeldes, lo que no deja de ser un indicio de su iustitia: «multos ad oboedienciam suam pacificis viis inducens, alios qui ex toto rebellare decreverant armorum viribus prostrans» (Duod. III 24 , p. 364). A continuación, se destacan sus desvelos por solucionar el cisma,

\footnotetext{
${ }^{45}$ Esta apreciación de rey justo se pone de relieve también en la Anacephaleosis, donde la semblanza del monarca comienza así: «Hic Enricus rex iusitiae magnus zelator fuit et in pace regna sua gubernavit» (Anacepahleosis, p. 659). También aquí, en las primeras líneas, se insiste en su mala salud y en las guerras que llevó a cabo contra Portugal (siempre con la técnica del asedio y nunca en campo abierto). Luego, al hablar de su proyecto de llevar la guerra contra Granada, relata también su muerte en Toledo, aunque nada dice de la preferencia del rey por ningún oficio determinado: «apud Toletum, aegritudine quae eum continue premebat vehementius invalescente, in die Natalis Domini albescente coelo diem vitae suae clausit extremum».
} 
para lo que celebró una importante reunión en Perpiñán, que luego daría sus frutos en Constanza. Una vez más, la muerte se hace presente cuando el rey había determinado proseguir su campaña contra los musulmanes. Su tránsito también fue beato, rodeado de los suyos y entregado a la oración. En esto, como señala Cartagena, este Fernando se pareció a su antecesor, Fernando III, cuya muerte también describió como modélica (Duod. III 20, p. 354).

Este rápido recorrido por la vida de ambos monarcas, donde se destacan dos de sus principales virtudes (iustitia y fortitudo, que se pone de manifiesto por su interés común en la guerra contra la musulmán) y la muerte ejemplar de ambos, no acaba aquí, pues don Alfonso no quiere dejar de lado otras varias virtudes que los convierten en verdaderos modelos de príncipes: su castidad; la modestia en sus vestidos y palabras; la seriedad con la que se comportaban a pesar de su corta edad; la prudencia de que hacían gala; su porte majestuoso, realzado por vestidos ricos, aunque honestos; su poco interés por la caza (frente a lo común entre los nobles); su sobriedad en el comer y el beber, e incluso su eutrapelia (un virtud de moda y con clara inspiración aristotélica, que nos pone tras la senda del homo facetus et urbanus que gozó de enorme éxito en las cortes europeas del quinientos) ${ }^{46}$.

No olvida, por supuesto, que ambos fueron ejemplos cabales de liberalidad y magnificencia (liberalitas et magnificentia), con lo que se completa el cuadro de las cuatro virtudes esenciales que todo buen príncipe ha de poseer. Y para demostrarlo, recurre a sus recuerdos personales, pues él asistió al inicio de las obras de la Cartuja de Miraflores, cuya construcción promovió Enrique III sin reparar en gastos. Igual de onerosa fue la embajada a Tamorlán, cuyo único propósito fue, en opinión del prelado burgalés, trabar amistad con un príncipe de tierras lejanas («despreciando gastos, sin sopesar ningún tipo de beneficio personal» [Duod. III 26, p. 377]). La magnificencia de Fernando se puso también de manifiesto en el agasajo con que recibió a sus invitados en Perpiñán. Pero en aras de la verdad, a don Alfonso no se le escapa un pequeño defecto: Enrique fue propenso a la ira, aunque nunca llegó a dañar a nadie. Incluso aquí, don Alfonso mitiga la mácula al elevar a la categoría de axioma que «la ira de los príncipes, si es comedida, [...] suele ser, en ocasiones, beneficiosa» (Duod. III 25, p. 369).

Acabados los elogios, llega el momento de cerrar esta tercera cuestión, en la que las vidas de estos dos soberanos vuelven a poner de manifiesto la

${ }^{46}$ Cartagena ofrece una cumplida definición de esta virtud que está presente en el ámbito cortesano. La eutrapelia aleja a los príncipes del juego y les lleva a divertirse con sus nobles «de forma graciosa mezclando a menudo lo jocoso con lo serio y lo serio con lo jocoso, con un prudente sentido del buen gusto» (Duod. III 27, p. 379). 
relevancia de las virtudes para obtener el juicio favorable de la historia. Como hombre de leyes, mentor de la nobleza y amante de las letras, Cartagena ofrece aquí un buen ejemplo de cómo poner los saberes al servicio de los demás. En este y en otros escritos suyos descubrimos al hombre que hay detrás, pues nunca sintió empacho por dejar constancia de su carácter y pensamiento. Su extremada racionalidad, propia de un jurista; su amor e interés por las letras, propias de un erudito; su responsabilidad política y moral, propias del buen consejero regio y del hombre de Iglesia que siempre fue, se dan cita en este Duodenarium, cuya lectura minuciosa no deja de depararnos sorpresas.

Recibido: 29/05/2018

Aceptado: 19/07/2018 


\title{
$\cos$
}

\section{Alfonso de CARTAGena y EL OFICIO DE Historiador: \\ LAS SEMBLANZAS DE PRÍNCIPES ANTIGUOS Y MODERNOS EN EL DUODENARIUM}

RESUMEN: El contacto permanente de don Alfonso de Cartagena con otros intelectuales del resto de Europa durante las sesiones del concilio de Basilea (1434-1439) ha de ser considerado un factor decisivo para entender la evolución de su pensamiento político y la aparición de nuevos intereses eruditos. No es en absoluto casual que don Alfonso comenzara a escribir el Duodenarium (c. 1442) poco después de regresar a Castilla y a petición de su amigo Fernán Pérez de Guzmán. Si se comparan el título y el contenido de la obra, queda claro que don Alfonso no pudo acabar la tarea encomendada, ya que solo respondió a cuatro de las doce preguntas que le remitió Pérez de Guzmán. Este artículo atiende a la tercera de ellas, en la que don Alfonso diserta acerca de su idea de la Historia y las obligaciones del historiador.

Palabras Clave: Alfonso de Cartagena. Fernán Pérez de Guzmán. Rodrigo Jiménez de Rada. Duodenarium. Epístola al conde de Haro. Anacephaleosis. Oracional. Concilio de Basilea. Humanismo. Renacimiento. Studia humanitatis. Cultura europea.

\section{Alfonso de Cartagena's Remarks on History and the Historians: Ancient AND Modern Princes PORTRAYED IN THE DUODENARIUM}

\begin{abstract}
The permanent contact with other European intellectuals during the sessions of the Council of Basel (1434-1439) must be considered as a fundamental factor to understand the evolution of Alfonso de Cartagena's political thought and the appearance of some new scholarly interests. Not by chance, don Alfonso began to write his Duodenarium (c. 1442) soon after his return to Castile, under the request of his friend Fernán Pérez de Guzmán. If compared title with contents, we see that don Alfonso could not end the work, since he only answered to four of the twelve questions posed by Pérez de Guzmán. This article focuses on the third, where don Alfonso explains his ideas about History and on the duties of historians.
\end{abstract}

Keywords: Alfonso de Cartagena. Fernán Pérez de Guzmán. Rodrigo Jiménez de Rada. Duodenarium. Epistle to the Count of Haro. Anacephaleosis. Oracional. Council of Basel; Humanism. Renaissance. Studia humanitatis. European culture. 